\title{
Designing Heterogeneous Catalysts for Renewable Catalysis Applications Using Metal Oxide Deposition
}

\author{
Yuan-Peng Du and Jeremy S. Luterbacher
}

\begin{abstract}
Heterogeneous catalysis has long been a workhorse for the chemical industry and will likely play a key role in the emerging area of renewable chemistry. However, renewable molecule streams pose unique challenges for heterogeneous catalysis due to their high oxygen content, frequent low volatility and the near constant presence of water. These constraints can often lead to the need for catalyst operation in harsh liquid phase conditions, which has compounded traditional catalyst deactivation issues. Oxygenated molecules are also frequently more reactive than petroleum-derived molecules, which creates a need for highly selective catalysts. Synthetic control over the nanostructured environment of catalytic active sites could facilitate the creation of both more stable and selective catalysts. In this review, we discuss the use of metal oxide deposition as an emerging strategy that can be used to synthesize and/or modify heterogeneous catalysts to introduce tailored nanostructures. Several important applications are reviewed, including the synthesis of high surface area mesoporous metal oxides, the enhancement of catalyst stability, and the improvement of catalyst selectivity.
\end{abstract}

Keywords: Metal oxide deposition · Nanotechnology · Renewable catalysis · Selectivity · Stability

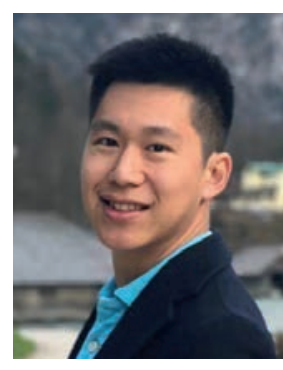

Yuan-Peng Du was born in Taipei, Taiwan. He earned his bachelor's degree in Chemistry at National Tsing Hua University and then moved to National Taiwan University where he obtained his master's degree. In his master project he studied how biomolecules affect the nucleation and crystallization processes of biomaterials. He is now a $\mathrm{PhD}$ candidate at LPDC, EPFL where he designs and synthesizes nanostructured catalysts for valorizing biomass-derived molecules.

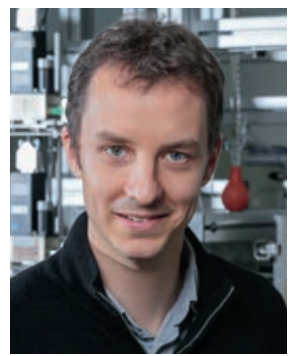

Jeremy Luterbacher was born in Switzerland in 1984 and received a BSc and MSc in chemical engineering from the École Polytechnique Fédérale in Lausanne (EPFL), Switzerland in 2007. He spent a year as a visiting scientist at the Massachusetts Institute of Technology in Jeff Tester's laboratory and then moved to Cornell University for a PhD under the supervision of Prof. Larry Walker. In 2012, Jeremy joined the University of Wisconsin-Madison as a Swiss National Science Foundation Postdoctoral Scholar under the supervision of Prof. Jim Dumesic. In 2014, Jeremy returned to EPFL as an Assistant Professor and head of the Laboratory of Sustainable and Catalytic Processing.

\section{Introduction}

With the increasing demand for sustainably sourced carbon molecules to replace petroleum-based bulk chemicals, catalytic processes will be increasingly solicited to turn renewable carbon feedstocks such as biomass and $\mathrm{CO}_{2}$ into platform molecules. A special emphasis will likely be placed on heterogeneous catalysis due to its lower cost and greater flexibility in terms of operating conditions compared to homogeneous and/or enzymatic catalysis. However, the diversity of oxygenated functional groups and the impurities contained in biomass-derived or $\mathrm{CO}_{2}$-derived feedstocks will impose increased constraints on heterogeneous catalysts to be both highly selective and robust. Preparing catalysts with such high selectivity and stability by simple impregnation or precipitation, which are the typical methods used in industry, is challenging. Therefore, searching for new synthetic approaches to design catalysts that can fulfill more stringent requirements for sustainable applications has become a major priority for the catalysis community.

In the past decade, the rapid development of nanoscale science has provided new synthetic techniques to tailor the structure of nanomaterials with controlled physical and chemical properties. Notable methods have featured the controlled deposition of thin oxide films with molecular precisions using gas- or liquid-phase techniques. ${ }^{[1-5]}$ A new class of heterogeneous catalysts featuring a configuration with a layer of metal oxide deposited over supported metallic nanoparticles and a metal oxide support, has emerged ever since the applications of metal oxide deposition techniques were extended beyond wafers to high surface area substrates. Specifically, these catalysts were 'overcoated' by post metal oxide deposition, making them distinct from conventional supported metal catalysts. Several interesting characteristics of overcoated catalysts were subsequently reported. In this review, we discuss the two principal coating techniques for nanomaterials and further discuss how metal oxide deposition can be used to synthesize heterogeneous catalysts with controlled nanostructures, higher selectivity and improved stability. 


\section{Gas- and Liquid-phase Overcoating Methods}

\subsection{Atomic Layer Deposition (ALD)}

Methods for depositing metal oxide overcoats on nanostructures can be categorized into two groups. The first features techniques based on chemical vapor deposition (CVD) where gaseous precursors react on a surface. Atomic layer deposition (ALD) is the most frequently used technique within this family for the design of heterogeneous catalysts because its self-limiting reactions lead to a precise control over the thickness and the conformity of the overlayers. ${ }^{[2]}$ The simplest ALD process is a binary (AB) precursor system. In this process, the first precursor (A) reacts with all the surface sites that are available on the substrates until the reaction is self-limited and a monolayer is formed. The remaining precursor $\mathrm{A}$ is then pumped out of the reaction chamber with a purging gas. Subsequently, the second precursor B is fed to react with the monolayer of grafted A, also in a similar self-limited fashion, which completes one ALD cycle (Fig. 1a). A common precursor A for metal oxide deposition are organometallic compounds such as alkoxides and alkyls. Water is the most frequently used precursor B but other reagents can also be employed. For instance, $\mathrm{NH}_{3}$ is used as a precursor and catalyst for $\mathrm{SiO}_{2}$ deposition because $\mathrm{Si}$ precursors such as silicon tetrachloride $\left(\mathrm{SiCl}_{4}\right)$ and tetraethoxysilane (TEOS) lead to low reaction rates within temperature ranges that are achievable in most ALD apparatuses $\left(30{ }^{\circ} \mathrm{C}\right.$ to $\left.250{ }^{\circ} \mathrm{C}\right) \cdot{ }^{[6]}$ In contrast, trimethylaluminum (TMA) is hydrolyzed by water with a high reaction rate, even close to room temperature, which makes TMA- $\mathrm{H}_{2} \mathrm{O}$ a standard precursor pair for $\mathrm{Al}_{2} \mathrm{O}_{3}$ deposition.

The ALD equipment for coating powder and other high surface area substrates is similar to that used for coating planar and wafer substrates. The main differences lie in the design of the substrate chamber because powder substrates usually entail longer deposition times and require additional features to improve particle dispersion and mass transfer. Because of the nature of high surface area substrates, mass transfer is usually significantly more limited than for wafers. A higher partial pressure of precursors can be used to accelerate mass transfer. However, nanoparticles can easily aggregate at the same time, which prevents conformal coatings and thus requires some sort of mechanical dispersion of particles. To address all of these issues, ALD can be performed on powder substrates in a fluidized bed reactor, where fluidization greatly increases dispersion and facilitates mass transfer of gaseous precursors that react with the fluidized particles (Fig. 1b). ${ }^{[1]}$ The substrate beds can even be further agitated by vibration or using a mechanical stirrer to induce fluidization in order to further decrease aggregation and mass transfer limitations. A more in-depth review of ALD reactor design is beyond the scope of this review but can be found elsewhere. ${ }^{[7]}$

\subsection{Sol-gel-based Deposition in Liquid Phase}

In addition to ALD, metal oxide deposition on nanoparticles can also be performed in solution using sol-gel processes. Sol-gel is a chemical method to synthesize inorganic materials (e.g. metal oxides and ceramics) through the transformation of precursors from monomers to oligomeric 'sols' and finally to a polymeric structure called 'gel'. ${ }^{[8,9]}$ The most common sol-gel precursors for metal oxides are metal alkoxides. Sol-gel reactions, similar to ALD processes, are initiated by the hydrolysis of the precursor. However, the further hydrolysis and condensation of precursors do not typically proceed in a self-limiting manner. In solution, partially condensed precursors first form colloidal sols, which further nucleate to form bigger nanoparticles by additional polycondensation and crosslinking. ${ }^{[10]}$ The Stöber method is a typical example of well-defined $\mathrm{SiO}_{2}$ nanoparticle synthesis using a sol-gel process. ${ }^{[11]}$ Typically, $\mathrm{SiO}_{2}$ particles are prepared in an ethanol solution with ammonia being added as a catalyst for hydrolysis/condensation reactions. The resulting $\mathrm{SiO}_{2}$ particles have a spherical shape and an extremely narrow particle size distribution, which result from the negatively charged seed surface at basic condition and the monomer addition based growth mechanism. ${ }^{[12,13]}$ Due to its simplicity and unique particle size control, this process has been extensively studied. Extension of the Stöber method showed that $\mathrm{SiO}_{2}$ can grow on the surface of various particles (i.e. the core material) to form a so-called 'core-shell' structure (Fig. 2a). This finding led to the developments of sol-gel coatings and such techniques have sparked many reports of synthesis methods and applications for core-shell nanomaterials.

Compared to ALD, sol-gel coating can be easily performed in any standard chemistry laboratory since specific ALD equipment is not required. Nevertheless, the deposition of metal oxides other than $\mathrm{SiO}_{2}$ usually requires further kinetic control, because most oxides have precursors that hydrolyze significantly faster than the typically used tetraethyl orthosilicate (TEOS) for producing silica. According to classical nucleation theory, the nucleation barrier of
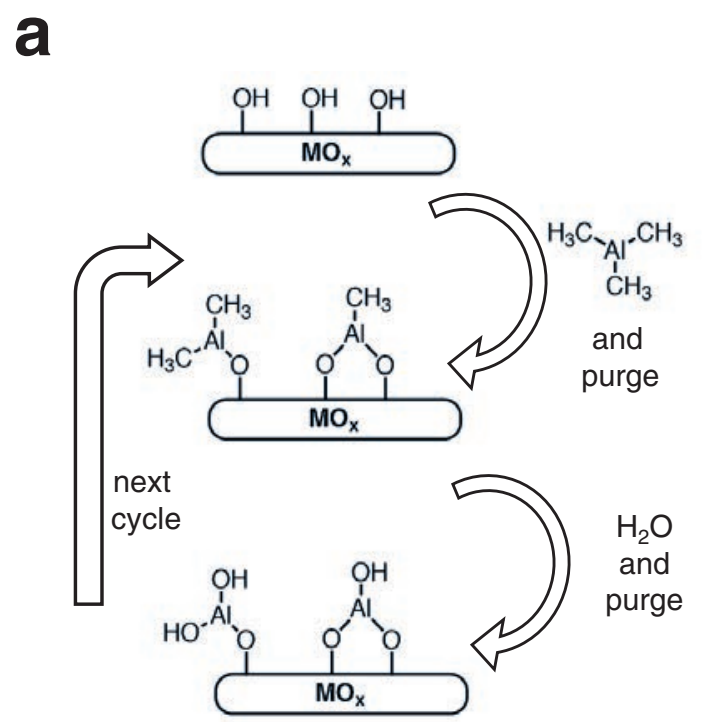

b

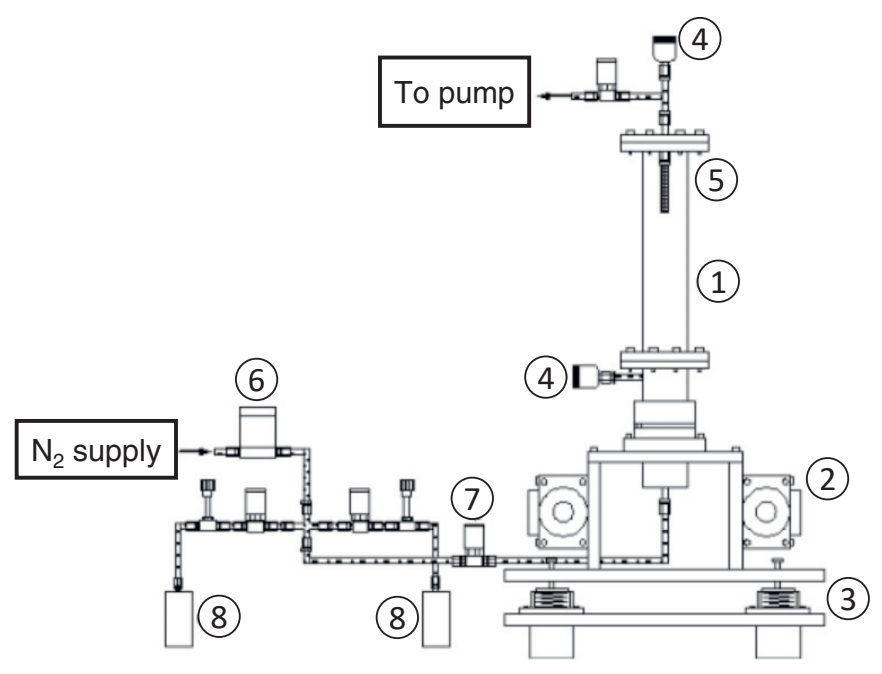

Fig. 1. (a) Steps of the ALD deposition cycle using trimethyl aluminum as precursor A and water as precursor B. (b) Schematic illustration of an ALD apparatus which is composed of (1) a reaction column, (2) vibro-motors, (3) spring supports, (4) pressure transducers, (5) a sintered-metal filter, (6) a mass flow controller, (7) pneumatic valves and (8) precursor containers. Adapted with permission from ref. [1]. Copyright 2005, John Wiley and Sons. 
homogeneous nucleation is higher than that of heterogeneous nucleation because homogeneous nucleation involves the formation of more interfaces between small nuclei and solvent molecules and thus leads to a significantly higher surface energy per substrate. In comparison, the surface energy of the seeds can be reduced when they nucleate on a substrate, which lowers the nucleation barrier of heterogeneous nucleation compared to homogeneous nucleation. ${ }^{[14]}$ Consequently, heterogeneous nucleation, and thus overcoating, are favored when the precursors have slow condensation kinetics, which is indicative of a high nucleation barrier. This process is observed in the case of the Stöber process and is used to form core-shell structures. In contrast, faster precursor hydrolysis/condensation rates generally imply that the nucleation energy barrier is fairly low and thus homogeneous nucleation occurs despite being less favored than heterogeneous growth. For instance, the high hydrolysis/condensation rates of aluminum sec-butoxide $\left(\mathrm{Al}\left({ }^{\mathrm{s}} \mathrm{BuO}\right)_{3}\right)$ generally result in its rapid homogeneous nucleation and formation of an $\mathrm{Al}_{2} \mathrm{O}_{3}$ precipitate. Therefore, alumina overcoating using sol-gel chemistry is more difficult than using ALD since both homogeneous and heterogeneous nucleation can occur simultaneously and lead to non-uniform coatings.

To ensure the preferential deposition of metal oxide on a substrate in sol-gel processes, there are two main strategies that have been reported in the literature. The first is to put metal alkoxides in contact with the hydroxyl groups on the substrates' surface in anhydrous conditions. After surface condensation, the unreacted precursor is removed and then the grafted metal alkoxide is hydrolyzed by water prior to the next grafting cycle. ${ }^{[15-17]}$ The disadvantage of this approach is that it uses high excesses of solvents for rinsing and sometimes even involves full drying of the substrate. We have developed an analogue to such processes where we injected a stoichiometrically limited quantity of precursor based on the estimated amount of precursor that could achieve a monolayer coverage on the substrate's surface by precursor volume projection. ${ }^{4]}$ This stoichiometric control avoided the use of a purging solvent or any excess precursor. Similar to ALD process, all graft- ing steps from all these methods can be repeated several times to control the overcoat's thickness. The method did lead to uniform coatings but they were significantly more porous than those achieved with gas-phase ALD.

The second strategy is to slow down the kinetics of metal alkoxides to avoid homogeneous nucleation, which can notably be done by using chelation agents or non-hydrolytic sol-gel (NHSG) chemistry. Both methods rely on reducing the hydrolysis/condensation rates of the precursors. Once the kinetics are slowed down, homogeneous nucleation can be further inhibited by slowly injecting the precursor into a suspension of the substrate, which limits the concentration of precursor while maximizing the presence of surface nucleation sites (Fig. 2b). ${ }^{[18]}$ This injection is performed at either high temperature (in the case of the NHSG method) or with ammonia (in the case of the chelation method) to initiate the sol-gel reaction.

Although metal oxide deposition in liquid phase is distinct from that in gas phase with respect to the instrumentation and technical procedures, both approaches have been used for the synthesis and design of catalytic materials. In the following sections, three catalyst applications using post-deposition strategies will be discussed.

\section{Synthesis of Mesoporous Metal Oxides by Overcoating}

As previously mentioned, thin film deposition techniques can be used to overcoat supported metal catalysts as a post modification strategy. Besides this application, thin film deposition can also be a powerful technique to synthesize metal oxides with high surface areas and controlled porous structures using templateassisted strategies. Metal oxides are one of the most common materials used in catalysis and more generally in the chemical industry due to their highly diverse properties and potential applications. Ordered mesoporous silicas were first synthesized using cetyltrimethylammonium bromide in the 1990s (including the well-known material MCM-41[20]). The potential of such materi- a<smiles>CCO[Si](OCC)(OCC)OCCO</smiles>

b

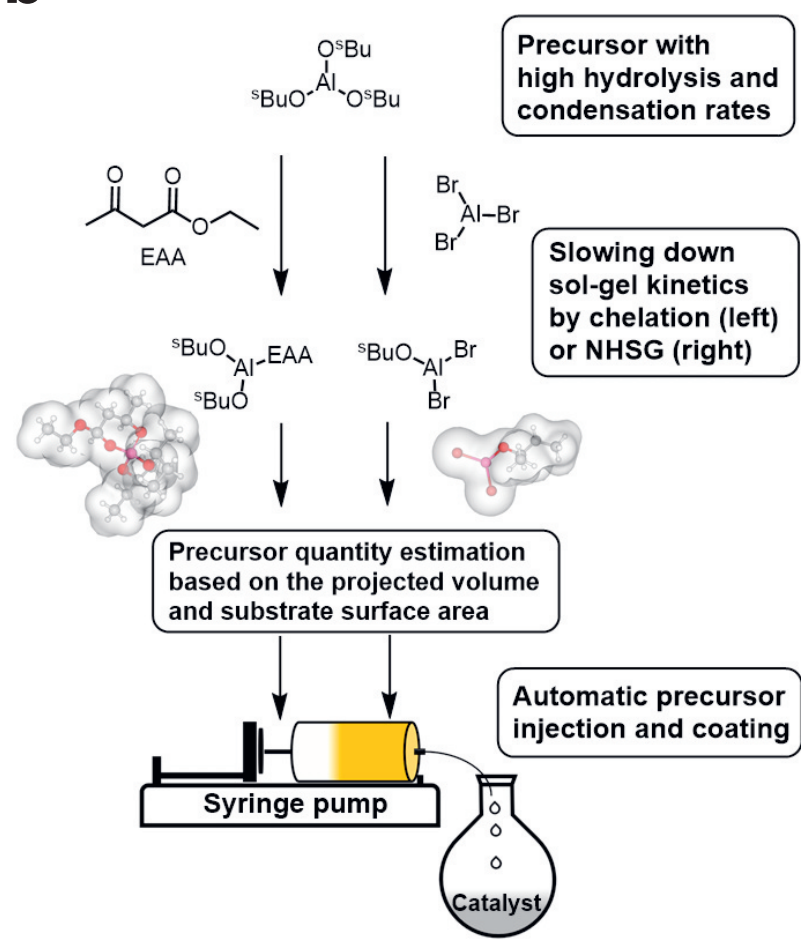

Fig. 2. (a) Growth mechanism during silica coating using sol-gel chemistry. According to both theoretical and experimental studies, metal alkoxide first forms nanoparticles (sols) by hydrolysis, which condense and then nucleate on the substrate. ${ }^{[10,19]}$ (b) Deposition procedure by kinetically controlled sol-gel chemistry illustrated for chemically modified aluminum precursors. 
als as catalysts was quickly recognized owing to their high surface area, ordered pore structure and thermal stability. Subsequently, the synthesis of mesoporous transition metal oxides has attracted a lot of attention. The unique catalytic properties of these metal oxides (e.g. redox activities, photo activity and acidity) have led to many applications of mesoporous metal oxides in catalysis science. Typically, template-assisted methods are used to synthesize mesoporous metal oxides. In such methods, the templating materials can be either a soft (e.g. surfactants or polymers) or a hard (e.g. pre-synthesized mesoporous silica) template. The experimental procedures of methods using soft templates are generally simpler than those using hard templates. However, the surface areas of mesoporous transition metal oxides prepared using soft templates are usually not as high as that of mesoporous silica. [21] To target a higher surface area, overcoating can be used in a specific hard templating approach, where the metal oxide of interest is deposited on mesoporous silica using either ALD or liquid phase techniques (Fig. 3a).
$\mathrm{TiO}_{2}$ (titania) is well-known for its photo activity and has many photocatalytic applications. Mahurin et al. first reported that titania could be deposited on SBA-15 using ALD with titanium tetrachloride and water as precursors and determined that $\mathrm{TiO}_{2}$ grew at the rate of $0.09 \mathrm{~nm}$ per ALD cycle. ${ }^{[22]}$ Instead of titanium tetrachloride, other authors also explored the use of titanium isopropoxide (TTIP) for $\mathrm{TiO}_{2}$ ALD. ${ }^{[23]}$ High surface area $\mathrm{TiO}_{2}$ was synthesized by depositing titania on different ordered mesoporous silica templates (MCM-41, SBA-15, and KCC-1) and their activities of photocatalytic dye degradation were tested. The ALD cycle conditions were found to have significant effects on the grain size of $\mathrm{TiO}_{2}$, which governed the photoactivity of these overcoated materials. Titania particles with a grain size at around $10 \mathrm{~nm}$, which were prepared by performing 60 ALD cycles on $\mathrm{KCC}-1$, showed the highest rate for degrading Rhodamine $\mathrm{B}$ dye.[23]

Attempts to use sol-gel methods to deposit $\mathrm{TiO}_{2}$ have also been made. As previously mentioned, the kinetics of metal alkoxide have to be controlled in order to avoid homogeneous nu-

a

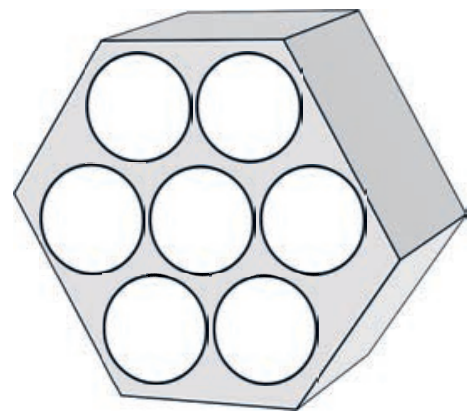

Mesoporous $\mathrm{SiO}_{2}$ template

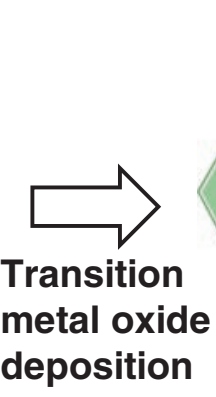

deposition

\section{Mesoporous transition} metal oxide

b
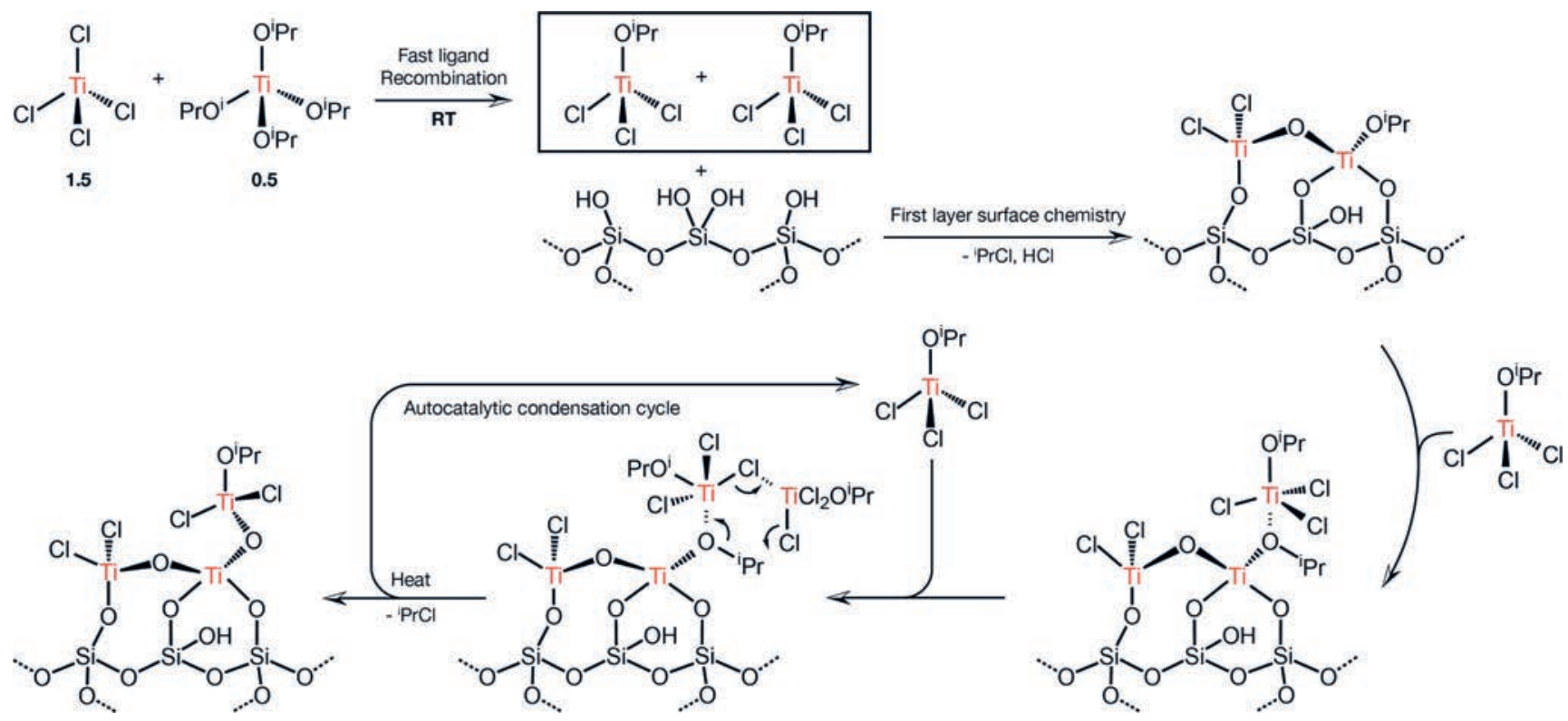

Fig. 3. (a) Synthesis of mesoporous transition metal oxides using a hard-templating method with overcoating. (b) Coating cycle and reaction mechanism of NHSG chemistry using $\mathrm{TiCl}_{4}$ and TTIP as precursors. Adapted with permission from ref. [25]. Copyright 2018, Elsevier. 
cleation. Perathoner et al. grafted TTIP in anhydrous conditions, which prevented any nucleation off the surface, leading to $\mathrm{TiO}$ being uniformly formed in the pore structure of SBA-15 after thermal treatment (the resulting material was denoted as $\mathrm{TiO}_{2} @$ SBA-15).[24] This TiO @SBA-15 had high surface area (above $500 \mathrm{~m}^{2} / \mathrm{g}$ ) and an ordered hexagonal pore structure according to $\mathrm{X}$-ray diffraction. The authors also suggested that a full monolayer coverage of $\mathrm{TiO}_{2}$ required two grafting cycles. However, multiple grafting steps were time consuming, which limited the practical applications of this method when a thicker overcoat was needed. To develop a more practical method, our group developed a kinetically controlled coating strategy based on NHSG chemistry. ${ }^{[25]}$ The NHSG precursor of $\mathrm{TiO}$ can be prepared by mixing TTIP and $\mathrm{TiCl}_{4}$ in a dry solvent. This leads to intermolecular ligand exchange and the formation of a mixed-ligand precursor that is stable at room temperature but condenses at $373 \mathrm{~K}$ (Fig. $3 b) .{ }^{[26,27]}$ Since no water is present, the oxygen is provided by the alkoxide ligand, while condensation liberates an alkyl halide (Fig. 3b). In this work, Héroguel et al. used a syringe pump to continuously inject this precursor into a heated SBA-15 suspension to initiate $\mathrm{TiO}_{2}$ deposition. The resulting titania overcoat is comparable in terms of conformity to those obtained from ALD processes, though slightly less uniform and usually containing some porosity. We also observed that the numbers of acid sites reached a maximum when six layers of titania were deposited. ${ }^{1} \mathrm{H}$ magic angle spinning solid-state NMR confirmed the presence of $(\mathrm{SiO})_{2}(\mathrm{TiO})-\mathrm{Si}-\mathrm{OH}$, which suggested that such interfacial sites and their quantity could be controlled by the overcoating process. The targeted mild Lewis acidity of interfacial sites led to a high selectivity and activity during 1-phenylethanol dehydration, especially compared to the reference HZSM-5 catalyst that had stronger acidity but catalyzed oligomer formation and quickly deactivated. More importantly, the overcoat thickness could be simply tuned by injecting a more concentrated precursor solution. Overall, this method provided a faster coating procedure in liquid media compared to the traditional grafting approaches.

The metal oxides with acidity are promising solid acids for catalyzing depolymerization and dehydration reactions, which are two important processes for valorizing lignocellulosic biomass. Specifically, niobium pentoxide (niobia) shows interesting acid properties, because it is one of the few metal oxides that possesses both Lewis and Brønsted acid sites. Pagán-Torres et al. reported the synthesis of mesoporous niobic acid using niobia ALD and an SBA-15 template. ${ }^{[28]}$ The overcoated SBA-15 showed not only an improved hydrothermal stability but also higher activities during the dehydration of secondary alcohols compared to a commercial bulk niobia catalyst. The improved hydrothermal stability and activities were attributed to the delayed phase transformation due to the formation of $\mathrm{Si}-\mathrm{O}-\mathrm{Nb}$ linkage and its higher surface area, respectively. Following this, we also developed a sol-gel mediated deposition of niobia on SBA-15. [5] The method once again relied on slowing down the hydrolysis and condensation rates of niobium(v) ethoxide by chelating the precursor using ethyl acetoacetate. Similar to the analogous ALD work, we observed that the amorphous structure of the overcoat had a higher thermal stability compared to bulk niobia, which preserved the number of acid sites during catalyst regeneration. The balanced ratio of Lewis and Brønsted acid sites on the overcoat was also favorable to the selective production of furfural during xylose dehydration. Besides $\mathrm{Nb}_{2} \mathrm{O}_{5}$, sulfonated $\mathrm{ZrO}_{2}$ is another attractive solid acid catalyst for sugar dehydration. Osatiashtiani et al. synthesized a mesoporous zirconia by repeatedly grafting zirconium propoxide on SBA-15. Between each cycle, the grafted SBA-15 was thoroughly washed with hexane to remove the unreacted precursor and re-hydrolyzed using water. The as-synthesized $\mathrm{ZrO}_{2}$ was subsequently treated with sulfuric acid to produce sulfonated $\mathrm{ZrO}_{2}$. The authors suggested that the SBA-15 with two grafting cycles and subsequent treatment with $0.02 \mathrm{M} \mathrm{H}_{2} \mathrm{SO}_{4}$ had an optimal Brönsted/Lewis acid site ratio, thus leading to a three-fold increase in 5-HMF yield from glucose dehydration comparing to that obtained from bulk zirconia.

\section{Nanoparticle Stabilization by Overcoating}

Sintering of nanoparticles is a common deactivation pathway that is frequently observed with supported metal catalysts. Sintering refers to the increase in nanoparticle size by particle migration and coalescence or/and Ostwald (atomic) ripening (Fig. 4a). ${ }^{[29,30]}$ Sintering causes irreversible loss of accessible metal sites because as nanoparticles grow, the ratio of surface atoms, which are the active sites to total atoms, irreversibly drops. Importantly, nanoparticle migration usually takes place at high temperatures, which are often used during catalyst regeneration. Therefore, even if the catalytic transformation occurs at low temperature, the regeneration may take place at higher temperatures, which could cause sintering and deactivation. Because the nanoparticles, especially those composed of noble metals, are often the costliest part of a catalyst, preventing nanoparticles from sintering and lowering their active surface area is of high interest to industry. Metal oxide deposition has recently emerged as a new strategy for designing sintering-resistant catalyst. The protective overcoat can either serve as a physical barrier and anchor nanoparticles by strong metal-metal oxide interaction ${ }^{[31]}$ or cap the undercoordinated atoms to prevent atomic ripening. ${ }^{[32]}$

Depositing silica on supported metal catalysts to mitigate particle sintering using the sol-gel technique was the earliest reported strategy because of its simpler experimental procedures. Lee et al. overcoated a $\mathrm{Pt} / \mathrm{SiO}_{2}$ catalyst with a $20 \mathrm{~nm}$ silica shell using a standard Stöber procedure and the resulting catalyst remained well-dispersed even after being calcined at $1075 \mathrm{~K}$ (Fig. 4b). ${ }^{[33]}$ In another study, a monolayer of silica was grafted onto a $\mathrm{Au} / \mathrm{TiO}_{2}$ catalyst that was used for $\mathrm{CO}$ oxidation and this modified catalyst showed a similar improved stability and reduced sintering. ${ }^{[34]}$ The recent advances in ALD technology and sol-gel synthesis techniques also enabled the design of catalysts with overcoats consisting of different transition metal oxides. Targeting other metal oxides besides silica for overcoating is worthwhile because silica is especially water-sensitive and many renewable streams tend to contain water. Lu et al. synthesized a coking and sintering resis$\operatorname{tant} \mathrm{Pd} / \mathrm{Al}_{2} \mathrm{O}_{3}$ catalyst by overcoating with $\mathrm{Al}_{2} \mathrm{O}_{3} \mathrm{ALD}$. The mean Pd particle size did not change after $28 \mathrm{~h}$ of time on stream, where the material catalyzed the oxidative dehydrogenation of ethane at $948 \mathrm{~K}$. In comparison, significant sintering was observed for the uncoated sample. ${ }^{[35]}$ Using a similar strategy to improve catalyst stability for liquid-phase biomass valorization applications was reported by O'Neill et al. where the authors synthesized an overcoated $\mathrm{Al}_{2} \mathrm{O}_{3} @ \mathrm{Cu} / \mathrm{Al}_{2} \mathrm{O}_{3}$ catalyst using ALD. ${ }^{[32]}$ This work demonstrated that overcoats could be used to stabilize base metals during liquid-phase furfural hydrogenation. The uncoated $\mathrm{Cu} /$ $\mathrm{Al}_{2} \mathrm{O}_{3}$ continuously and irreversibly deactivated as particle sintering took place during both the reaction and regeneration steps. In contrast, the overcoated catalyst showed the same activity after four regeneration cycles. Motivated by this work, we developed a new kinetically controlled sol-gel method to overcoat $\mathrm{Al}_{2} \mathrm{O}_{3}$. This method produced an analogous $\mathrm{Al}_{2} \mathrm{O}_{3} @ \mathrm{Cu} / \mathrm{Al}_{2} \mathrm{O}_{3}$ catalyst with similar sintering-resistant properties during liquid-phase furfural hydrogenation reactions. Therefore, this liquid-phase method offered a potentially more cost effective alternative to overcoating alumina and improving the stability of base metal catalyst without the use of expensive gas-phase ALD equipment. ${ }^{[18]}$

Although the overcoat is a powerful tool for stabilizing nanoparticle, it may interact with the metal particles and can even completely deactivate the catalyst. Lee et al. observed that Co reacted with the alumina precursor during ALD to form an irreducible cobalt aluminate phase after calcination. ${ }^{[36]}$ Consequently, 
a

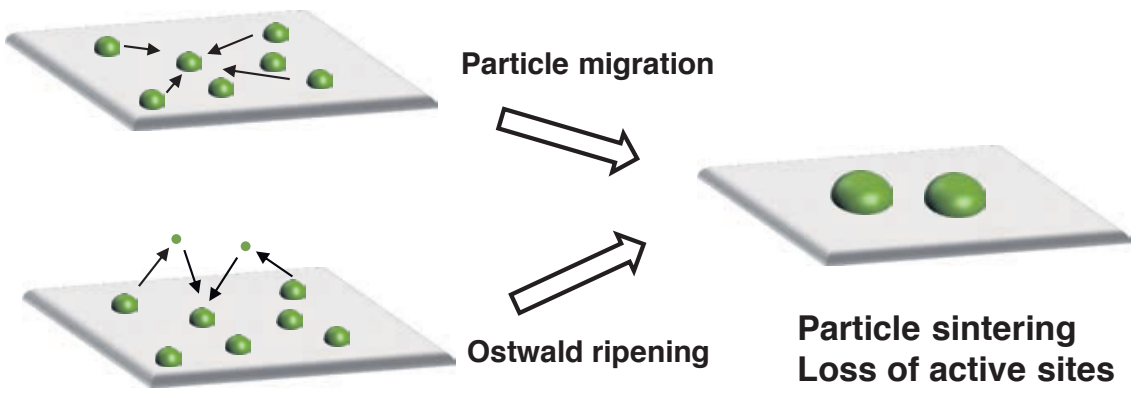

b
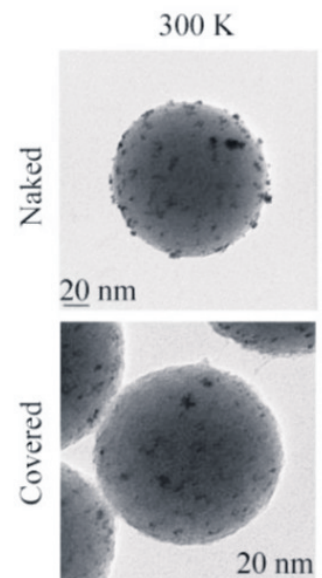

$875 \mathrm{~K}$

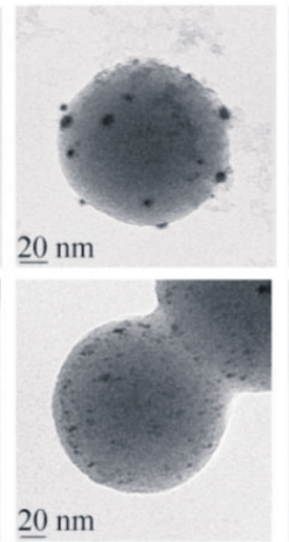

$975 \mathrm{~K}$

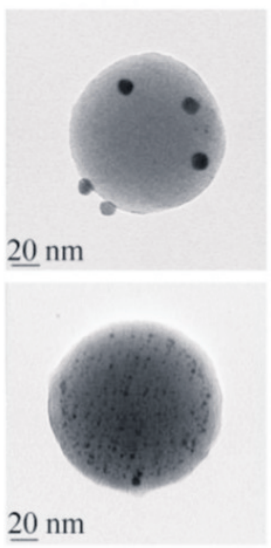

$1075 \mathrm{~K}$

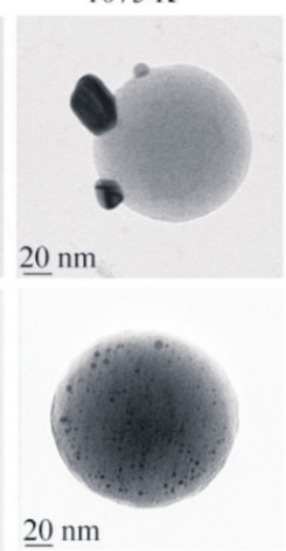

Fig. 4. (a) Illustration of the two main mechanisms of particle sintering of supported metal catalysts. (b) The effect of silica overcoat on the stability of $\mathrm{Pt} / \mathrm{SiO}_{2}$. Sintering of $\mathrm{Pt}$ can be observed when the uncoated catalyst was thermally treated above $875 \mathrm{~K}$ whereas the overcoated $\mathrm{Pt} / \mathrm{SiO}{ }_{2}$ still remained well-dispersed at 1075 K. Reprinted with permission from ref. [33]. Copyright 2011, Springer Nature.

the overcoated Co catalyst showed no hydrogenation activity. To avoid the formation of cobalt aluminate, the authors overcoated the cobalt catalyst with $\mathrm{TiO}_{2}$. Intriguingly, they found that the $\mathrm{TiO}_{2}$ overcoat suppressed not only sintering but also leaching when hydrogenating furfuryl alcohol in aqueous phase. This stability enhancement was ascribed to the capping of undercoordinated Co atoms. This capping can also lead to negative effects as the second common issue of metal oxide deposition, where the accessibility of nanoparticles may be limited when they are masked by the overcoat. Possible solutions include increasing the porosity by either thermal treatment or surface etching. Thermal treatment is the most common way to reactivate an overcoated catalyst and is usually necessary to get reasonable activities when using ALD. The increase in surface area of overcoated catalysts after calcination suggested that the overcoat was 'cracked', presumably by structural reorganization at high temperature, which led metal sites to be re-exposed. ${ }^{[32,35,36]} \mathrm{NaOH}$ was also used to etch overcoats like those made of $\mathrm{SiO}_{2}$ to increase the accessibility of active sites, which was shown with a $\mathrm{SiO}_{2} @ \mathrm{Pt} / \mathrm{SiO}_{2}$ catalyst used for the hydrogenation of 2-butenes. ${ }^{[37]}$

Protecting nanoparticles with organic ligands or polymers during coating procedures is another strategy to increase their accessibility. Lu et al. demonstrated that polyvinylpyrolidone (PVP) can serve as a protective ligand when coating $\mathrm{Pt} / \mathrm{TiO}$, with $\mathrm{SiO}_{2}$ using sol-gel chemistry. ${ }^{[38]}$ This method relied on controlling the PVP density on the Pt surface, which played a pivotal role during the nucleation of the silica overcoat. Specifically, silica growth was inhibited when Pt particles had a relatively low PVP coverage, whereas significant PVP coverage favored silica nucleation. This effect favored the growth of silica on the $\mathrm{TiO}_{2}$ support, thus creating an 'island' structure and leaving more nanoparticles accessible (Fig. 5a). As a result, the catalyst with a $2.8 \mathrm{~nm}$ silica overcoat still featured similar reaction rates to the uncoated sam- ple when catalyzing the reduction of p-nitrophenol. Similar strategies have also been reported for ALD overcoating. A new lowtemperature ABC-type ALD technique was developed in 2010 to synthesize a highly dispersed $\mathrm{TiO}_{2} @ \mathrm{Pd} / \mathrm{TiO}_{2}$ catalyst. ${ }^{[39]} \mathrm{Up}$ to now we have discussed AB-type ALD (i.e. one precursor, A, and one counter-reactant, B), which is the most common method for coating heterogeneous catalysts. In this new strategy, palladium (II) hexafluoroacetylacetonate, $\left[\mathrm{Pd}(\mathrm{hfac})_{2}\right]$, TTIP, and water were used as precursors A, B and C, respectively. The substrate was a pure $\mathrm{TiO}_{2}$ support without nanoparticles and each cycle featured an extra step, where the Pd precursor was introduced and $\mathrm{Pd}$ nanoparticles formed from the nucleation of $\mathrm{Pd}(\mathrm{hfac})_{2}$, on the support. During this nucleation step, some aggregation occurs between Pd complexes presumably through ligand dissociation and formation of Pt-Pt bonds. Subsequently, because the hfac ligand on Pd did not react with water below $473 \mathrm{~K}$, the overcoat could selectively grow on the support (with subsequent exposures of precursors B and C) without blocking the Pd particles (Fig. 5b). Finally, the ligand could be removed using a mild thermal treatment $\left(200^{\circ} \mathrm{C}\right)$, which resulted in a catalyst with a very small mean particle size $(\sim 1 \mathrm{~nm})$. CO chemisorption was used to quantify the $\mathrm{Pd}$ sites and the result was proportional to the number of Pd ALD cycles, indicating that the strategy led to a high Pd accessibility.

\section{Engineering Catalyst Surface Functionality and Active Sites}

The progress of more advanced characterization and computational tools have provided increasing theoretical and experimental insight into the active sites on catalyst surfaces. ${ }^{[40,41]}$ Notably, the interaction between metal nanoparticle and support has increasingly been recognized for its key role in catalysis. ${ }^{[42]}$ Indeed, in some cases, the metal oxides do not simply serve as a carrier of metal nanoparticles but play an active role in catalysis. When 
a

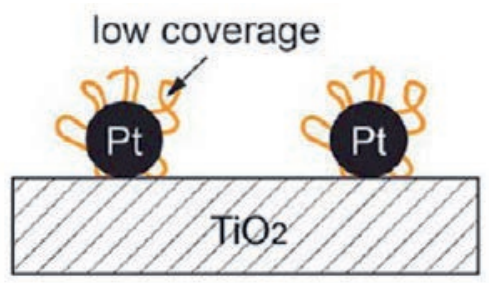

polyvinylpyrrolidone

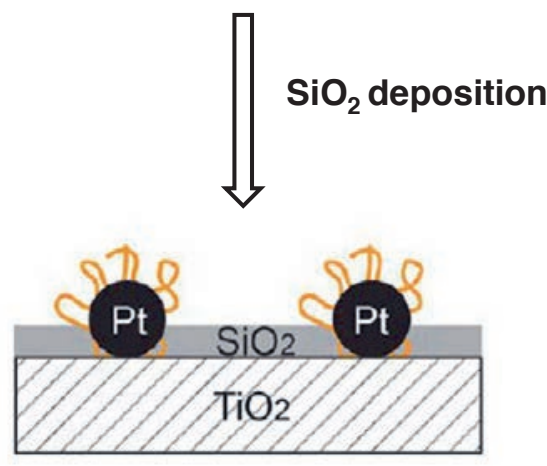

b

a)

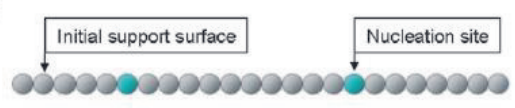

b)

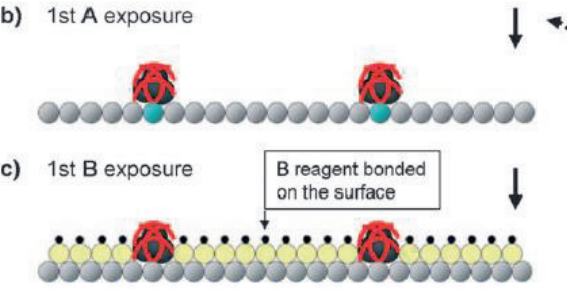

d) $1 \mathrm{st} \mathrm{C}$ exposure

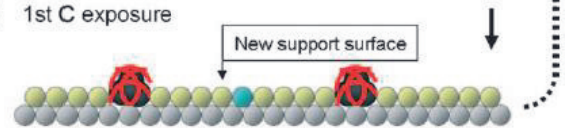

e) Multiple $A B C$ cycles

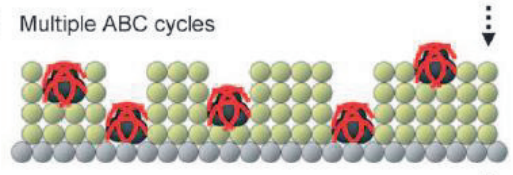

f)

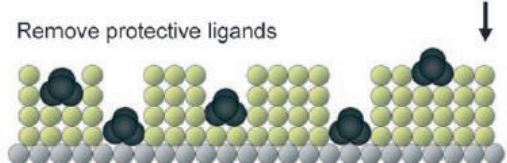

Fig. 5. Strategies for minimizing the blockage of nanoparticles using protective ligands during metal oxide deposition (a) in a sol-gel process, using PVP and (b) in an ALD process using an unhydrolyzable hfac ligand. Adapted with permission from ref. [38], copyright 2013, American Chemical Society and ref. [39], copyright 2010, John Wiley and Sons, respectively.

this occurs, the catalytic properties of nanoparticles on different metal oxide supports can vary significantly. Recent findings also suggested that some reactions are actually only catalyzed by the metal-support interfaces instead of the nanoparticles alone. ${ }^{[43-45]}$ In this context, metal oxide deposition has been proposed as a strategy to rationally design supported metal catalysts by either modulating the properties of nanoparticles or designing and/or increasing the number of interfacial sites (Fig. 6). ${ }^{[43,46]}$ One illustrative example of modifying the nanoparticle functionality is the case of $\mathrm{ZrO}_{2} @ \mathrm{Pd} / \mathrm{Al}_{2} \mathrm{O}_{3}$ used for methane oxidation. The assynthesis catalyst with a $1 \mathrm{~nm}$ zirconia overcoat prepared using ALD showed a limited activity for methane oxidation. However, the overcoated catalyst could be reactivated after heating to 1073 $\mathrm{K}$ (due to the cracking phenomenon described in the previous section) and showed a higher rate than the fresh $\mathrm{Pd} / \mathrm{Al}_{2} \mathrm{O}_{3}$ for methane conversion. The authors attributed the improved activity to the intimate contact between the $\mathrm{ZrO}_{2}$ and nanoparticles. The reducible overcoat could have stabilized $\mathrm{PdO}$, which was hypothesized to be one of the active sites for methane oxidation. ${ }^{[47]}$ In addition to altering the properties of nanoparticles, metal oxide overcoats can also physically engineer the microenvironment where the nanoparticles are located thereby directing the reaction towards a more favorable pathway. Yi at al. used ALD to synthesize an $\mathrm{Al}_{2} \mathrm{O}_{3} @ \mathrm{Pd} /$ $\mathrm{Al}_{2} \mathrm{O}_{3}$ catalyst for the selective hydrogenation of 1,3-butadiene. Unlike when using the uncoated Pd catalyst, where the selectivity towards butene significantly dropped at above $20 \%$ conversion, $\mathrm{Al}_{2} \mathrm{O}_{3} @ \mathrm{Pd} / \mathrm{Al}_{2} \mathrm{O}_{3}$ could still selectively produce butene at $100 \%$ conversion without over-hydrogenation. This significant selectivity improvement was attributed to the microporous structure of the alumina overcoat. The authors suggested that the adsorption of butene was limited by the physical structures around the Pd sites within the micropores of overcoat, which prevented butene from adsorbing and further hydrogenating.

Overcoating is also a powerful approach to engineer the functionality of a catalyst surface. In particular, depositing a new metal oxide overcoat that is different from the pristine support can lead to the formation of a mixed oxide interface that possesses distinct chemical properties. Silica-alumina is a well-known mixed oxide material with unique acid properties and is used as a Brønsted acid catalyst in the petroleum industry. The Brønsted acidity has been attributed to the presence of aluminum atoms in the silica network, which stabilizes the conjugated base of deprotonated silanols. ${ }^{[48]}$ Therefore, overcoating silica on an alumina surface or the reverse can lead to the formation of Brønsted acid sites at the interface between overcoat and support. Ardagh et al. overcoated silica on a commercial alumina with varying thickness using a standard Stöber method. ${ }^{[49]}$ They found that the thickness of the overcoat significantly affected the acid properties. Brønsted acid sites were observed after overcoating $2 \mathrm{~nm}$ of silica on the surface whereas the surface became inert when the overcoat was thicker than $5 \mathrm{~nm}$. The optimized $\mathrm{SiO}_{2} @ \mathrm{Al}_{2} \mathrm{O}_{3}$ catalyst showed a similar activity for the dealkylation of 1,3,5 triisopropylbenzene to commercial $\mathrm{SiO}_{2}-\mathrm{Al}_{2} \mathrm{O}_{3}$ and zeolites. Moreover, applying the same strategy to a supported metal catalyst can create Brønsted acid sites that have a more intimate contact with nanoparticles. Such interfacial Brønsted acid-metal sites can modulate the selectivity during the hydrogenation of cinnamaldehyde, which was demonstrated in recent work published by Weng et al. ${ }^{[50]}$ Similar to the aforementioned $\mathrm{SiO}_{2} @ \mathrm{Al}_{2} \mathrm{O}_{3}$ catalyst, Brønsted acid sites formed after overcoating $\mathrm{SiO}_{2}$ on $\mathrm{Pt} / \mathrm{Al}_{2} \mathrm{O}_{3}$ with three ALD cycles (leading to approximately a half a monolayer of silica). Importantly, the selectivity towards cinnamyl alcohol was significantly improved after overcoating. The catalyst with four ALD cycles showed the highest selectivity (85\%) whereas the uncoated $\mathrm{Pt} / \mathrm{Al}_{2} \mathrm{O}_{3}$ led to a selectivity of only $25 \%$, which suggested that the synergy between Brønsted acid sites and Pt particles played an important role in the selective hydrogenation of the unsaturated aldehyde.

Other interesting applications of the bi-functionality created at the interface of metal and acid sites include hydrodeoxygenation reactions (HDO). ${ }^{[51]}$ HDO is a catalytic route often used to remove oxygen from oxygenated molecules. This process is particularly relevant in the context of biofuel production from 


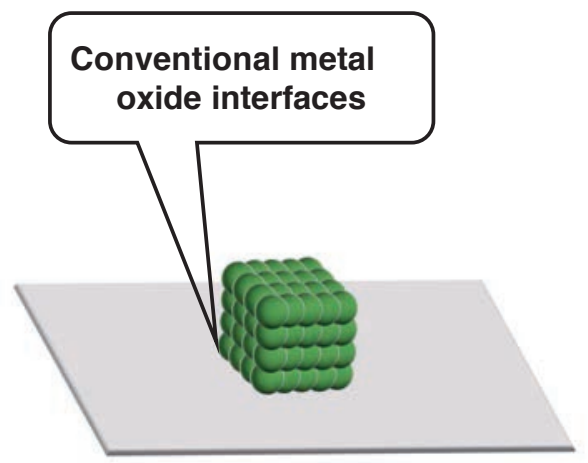

Uncoated supported metal catalyst

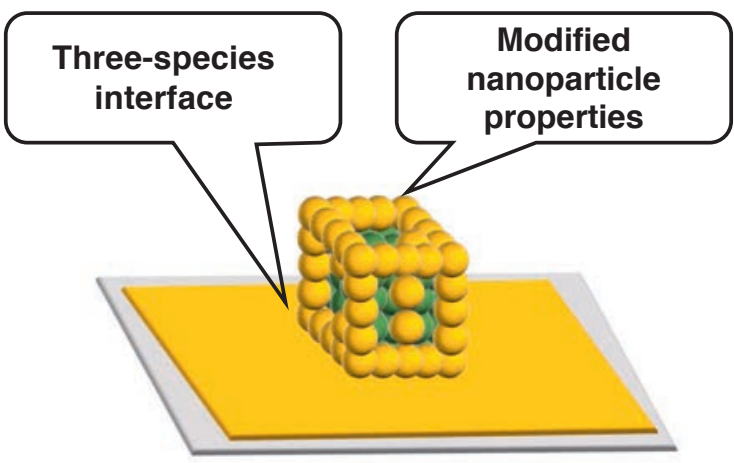

Overcoated supported metal catalyst

Fig. 6. Schematic illustration of the modification of active sites by overcoating supported metal nanoparticles.

biomass since bio-based molecules generally contain significant quantities of oxygen, which decreases the energy density and can affect the stability and corrosiveness of the fuel. Among these feedstocks, lignin-derived phenolic molecules are promising candidates for producing biofuel, due to their aromatic nature, comparatively low oxygen content and carbon chain length (native lignin is composed of phenyl propane, i.e. $\mathrm{C}_{9}$, units). ${ }^{[52]}$ Therefore, the HDO of lignin model compounds (e.g. guaiacol, phenol and anisole) have been extensively studied to elucidate the reaction mechanism. ${ }^{[53,54]}$ According to these studies, HDO of these phenolic molecules requires a metallic site and an acid site and the importance of the proximity of these two active species has been recognized in several studies. ${ }^{[54-56]}$ Overcoating is an emerging approach to create and tailor these interfacial sites in order to effectively cleave functional groups containing oxygen. We have recently studied the HDO of 3-propyl phenol over a $\mathrm{Pt} / \mathrm{SiO}_{2}$ catalyst overcoated with $\mathrm{TiO}_{2}$ using a non-hydrolytic sol-gel method.[25] Without the overcoat, the material showed very low HDO activity and produced mostly oxygenated ring hydrogenation products. In contrast, the overcoated $\mathrm{TiO}_{2} @ \mathrm{Pt} / \mathrm{SiO}_{2}$ showed 90\% selectivity towards deoxygenated product (propyl cyclohexane) due to the Lewis acidity imparted by the overcoat and specifically the close proximity of the $\mathrm{SiO}_{2}-\mathrm{TiO}_{2}$ interface with the platinum. We also found that $\mathrm{Pt} / \mathrm{TiO}_{2}$ led to a low selectivity that was comparable to the uncoated sample, demonstrating that the interface of platinum and titania alone could not explain the higher deoxygenation of the overcoated catalyst. Similar results were also in another study from our group by Du et al. ${ }^{[18]}$ where the same HDO reaction was run over overcoated $\mathrm{Al}_{2} \mathrm{O}_{3} @ \mathrm{Pt} / \mathrm{SBA}-15$ catalysts. The HDO activities of $\mathrm{Al}_{2} \mathrm{O}_{3} @ \mathrm{Pt} / \mathrm{SBA}-15$ overcoated by using either an NHSG or chelated precursor method were compared. Intriguingly, the Pt/SBA-15 with a denser $\mathrm{Al}_{2} \mathrm{O}_{3}$ overcoat synthesized using the NHSG method, led to a much higher selectivity towards propyl cyclohexane. The more porous overcoat that was prepared from the chelated precursor showed a moderate selectivity $(40 \%$ at $90 \%$ conversion) that was similar to the control $\mathrm{Pt} / \mathrm{Al}_{2} \mathrm{O}_{3}$ catalyst, which re-emphasized the pivotal role that interfacial metal-acid sites play on the HDO of lignin monomers.

\section{Conclusions and Outlook}

We presented an overview of how metal oxide deposition was developed as a versatile toolbox for designing unique nanostructured catalysts. In numerous studies, researchers have shown that overcoated materials can display quite distinct physical and/ or chemical properties compared to their uncoated counterparts. Consequently, this post modification strategy provides pathways to rationally design heterogeneous catalysts when high stability and/or support-metal interfacial sites are beneficial. Catalyst stability is usually a prerequisite for any industrial catalyst but it is a particular challenge when processing renewable substrates. These reactions are usually carried out in liquid phase where the loss of surface area of support or nanoparticle by phase transformation, sintering or leaching is particularly pronounced. Overcoating metal oxides on mesoporous silica templates can serve as an effective approach for synthesizing various metal oxides with high accessible surface areas and better stability than their bulk counterparts. In some cases, the presence of new metal-O-Si units improves the hydrothermal stability of the support, which makes these overcoated materials more suitable for biomass processing in liquid phase. On the other hand, particle sintering irreversibly deactivates catalysts in both liquid- and gas-phase reactions. Depositing metal oxides can prevent the migration of nanoparticles and/or passivate the undercoordinated metallic atoms to minimize Ostwald ripening. Despite these successes, one area of future development for stable catalysts using overcoating methods could be to minimize the loss of active sites through the blockage caused by the overcoats. Although strategies for protecting nanoparticles in both liquid- and gas-phase coating procedures have been proposed, such methods have only been reported for noble metal-based catalysts $(\mathrm{Pd}$ and $\mathrm{Pt})$. Extending these strategies to other metals, especially base metals, which have a significantly lower cost, could facilitate the design of stable and inexpensive catalysts with a maximized activity.

Finally, overcoating can be used to tailor the micro-environment of nanoparticles for specific purposes. The intimate contact between nanoparticles and metal oxide can be maximized with the formation of overcoats and create unique interfacial sites between the metal, support and overcoat, which can lead to unique chemical properties and further improve catalytic activities. Notably, depositing acidic metal oxides can impart bifunctionality to catalyst surfaces. In contrast to the case where nanoparticles are simply supported on a solid acid, overcoated catalysts have a larger number of acid-metal interfaces and such interfacial sites are highly active, especially for the cleavage of $\mathrm{C}-\mathrm{O}$ bonds by $\mathrm{HDO}$, which is a promising catalytic route to produce biofuels from lignocellulosic biomass. Nevertheless, the rational design of bi-functional catalysts could still be greatly improved by gaining a better understanding of mechanistic effects on the reactions catalyzed by the interfacial sites created in overcoated materials. Understanding the reaction pathways and intermediates on these sites at the atomic level in order to provide the mechanistic insight of the selectivity improvements would be a helpful avenue to build structure-reactivity relations. Such studies could involve complementary theoretical and analytical investigations like combining density functional theory with high-resolution microscopy and in situ spectroscopies. Ultimately, a clearer mechanistic picture of the interaction between the overcoat-metal-support interface and the reactant might enable the rational design of the complex nanostructured catalysts that are increasingly needed to process renewable feedstocks. 


\section{Acknowledgements}

This work was supported by the European Research Council (ERC) under the European Union's Horizon 2020 research and innovation program (Starting grant: CATACOAT, No 758653). This work was also accomplished within the framework of the Swiss Competence Center for Bioenergy Research (SCCER-BIOSWEET).

Received: July 19, 2019

[1] L. F. Hakim, J. Blackson, S. M. George, A. W. Weimer, Chem. Vapor Dep. $2005,11,420$

[2] M. Leskelä, M. Ritala, Angew. Chem. Int. Ed. 2003, 42, 5548.

[3] W. Li, J. Yang, Z. Wu, J. Wang, B. Li, S. Feng, Y. Deng, F. Zhang, D. Zhao, J. Am. Chem. Soc. 2012, 134, 11864.

[4] F. Héroguel, B. P. Le Monnier, K. S. Brown, J. C. Siu, J. S. Luterbacher, Appl. Catal. B: Environ. 2017, 218, 643

[5] Y.-P. Du, F. Héroguel, X. Trung Nguyen, J. S. Luterbacher, J. Mater. Chem A 2019, doi: 10.1039/C9TA01459D

[6] B. J. O'Neill, D. H. K. Jackson, J. Lee, C. Canlas, P. C. Stair, C. L. Marshall, J. W. Elam, T. F. Kuech, J. A. Dumesic, G. W. Huber, ACS Catal. 2015, 5, 1804.

[7] D. Longrie, D. Deduytsche, C. Detavernier, J. Vacuum Sci. Technol. A 2013, 32,010802 .

[8] C. J. Brinker, G. W. Scherer, 'Sol-Gel Science: The Physics and Chemistry of Sol-Gel Processing', Academic Press, 2013.

[9] A. E. Danks, S. R. Hall, Z. Schnepp, Mater. Horizons 2016, 3, 91.

[10] K. S. Brown, C. Saggese, B. P. Le Monnier, F. Héroguel, J. S. Luterbacher, J. Phys. Chem. C 2018, 122, 6713.

[11] W. Stöber, A. Fink, E. Bohn, J. Coll. Interf. Sci. 1968, 26, 62

[12] T. Matsoukas, E. Gulari, J. Coll. Interf. Sci. 1988, 124, 252.

[13] Y. Han, Z. Lu, Z. Teng, J. Liang, Z. Guo, D. Wang, M.-Y. Han, W. Yang, Langmuir 2017, 33, 5879.

[14] K. F. Kelton, A. L. Greer, 'Nucleation in Condensed Matter: Applications in Materials and Biology', Elsevier, 2010.

[15] I. Ichinose, H. Senzu, T. Kunitake, Chem. Lett. 1996, 831.

[16] Y. Wu, D. Döhler, M. Barr, E. Oks, M. Wolf, L. Santinacci, J. Bachmann, Nano Lett. 2015, 15, 6379.

[17] A. Osatiashtiani, A. F. Lee, M. Granollers, D. R. Brown, L. Olivi, G. Morales, J. A. Melero, K. Wilson, ACS Catal. 2015, 5, 4345.

[18] Y.-P. Du, F. Héroguel, J. S. Luterbacher, Small 2018, 14, 1801733.

[19] H. Okudera, A. Hozumi, Thin Solid Films 2003, 434, 62.

[20] C. T. Kresge, M. E. Leonowicz, W. J. Roth, J. C. Vartuli, J. S. Beck, Nature 1992, 359, 710 .

[21] P. Yang, D. Zhao, D. I. Margolese, B. F. Chmelka, G. D. Stucky, Nature 1998, 396, 152

[22] S. Mahurin, L. Bao, W. Yan, C. Liang, S. Dai, J. Non-Crystall. Solids 2006, 352,3280 .

[23] R. Singh, R. Bapat, L. Qin, H. Feng, V. Polshettiwar, ACS Catal. 2016, 6, 2770.

[24] S. Perathoner, P. Lanzafame, R. Passalacqua, G. Centi, R. Schlögl, D. S. Su, Micropor. Mesopor. Mater. 2006, 90, 347.
[25] F. Héroguel, L. Silvioli, Y.-P. Du, J. S. Luterbacher, J. Catal. 2018, 358, 50.

[26] D. P. Debecker, V. Hulea, P. H. Mutin, Appl. Catal. A: Gen. 2013, 451, 192.

[27] W. Yan, S. M. Mahurin, S. H. Overbury, S. Dai, Chem. Mater. 2005, 17, 1923.

[28] Y. J. Pagán-Torres, J. M. R. Gallo, D. Wang, H. N. Pham, J. A. Libera, C. L. Marshall, J. W. Elam, A. K. Datye, J. A. Dumesic, ACS Catal. 2011, 1, 1234.

[29] F. Héroguel, B. Rozmysłowicz, J. S. Luterbacher, Chimia 2015, 69, 582.

[30] E. D. Goodman, J. A. Schwalbe, M. Cargnello, ACS Catal. 2017, 7156.

[31] X. Liu, Q. Zhu, Y. Lang, K. Cao, S. Chu, B. Shan, R. Chen, Angew. Chem. 2017, 129, 1670

[32] B. J. O'Neill, D. H. K. Jackson, A. J. Crisci, C. A. Farberow, F. Shi, A. C. Alba-Rubio, J. Lu, P. J. Dietrich, X. Gu, C. L. Marshall, P. C. Stair, J. W. Elam, J. T. Miller, F. H. Ribeiro, P. M. Voyles, J. Greeley, M. Mavrikakis, S. L. Scott, T. F. Kuech, J. A. Dumesic, Angew. Chem. Int. Ed. 2013, 52, 13808.

[33] I. Lee, Q. Zhang, J. Ge, Y. Yin, F. Zaera, Nano Res. 2011, 4, 115.

[34] H. Zhu, Z. Ma, S. H. Overbury, S. Dai, Catal. Lett. 2007, 116, 128

[35] J. Lu, B. Fu, M. C. Kung, G. Xiao, J. W. Elam, H. H. Kung, P. C. Stair, Science 2012, 335, 1205.

[36] J. Lee, D. H. K. Jackson, T. Li, R. E. Winans, J. A. Dumesic, T. F. Kuech, G. W. Huber, Ener. Environ. Sci. 2014, 7, 1657.

[37] Q. Zhang, I. Lee, J. Ge, F. Zaera, Y. Yin, Adv. Funct. Mater. 2010, 20, 2201.

[38] P. Lu, C. T. Campbell, Y. Xia, Nano Lett. 2013, 13, 4957.

[39] J. Lu, P. C. Stair, Angew. Chem. Int. Ed. 2010, 49, 2547.

[40] A. I. Frenkel, J. A. Rodriguez, J. G. Chen, ACS Catal. 2012, 2, 2269.

[41] J. K. Nørskov, T. Bligaard, J. Rossmeisl, C. H. Christensen, Nat. Chem. 2009, 1, 37.

[42] S. J. Tauster, S. C. Fung, R. T. K. Baker, J. A. Horsley, Science 1981, 211, 1121

[43] I. Ro, J. Resasco, P. Christopher, ACS Catal. 2018, 8, 7368.

[44] D. Albani, Q. Li, G. Vilé, S. Mitchell, N. Almora-Barrios, P. T. Witte, N. López, J. Pérez-Ramírez, Green Chem. 2017, 19, 2361.

[45] J. Lu, S. Behtash, O. Mamun, A. Heyden, ACS Catal. 2015, 5, 2423.

[46] J. Zhang, J. W. Medlin, Surf. Sci. Rep. 2018, 73, 117.

[47] T. M. Onn, S. Zhang, L. Arroyo-Ramirez, Y.-C. Chung, G. W. Graham, X. Pan, R. J. Gorte, ACS Catal. 2015, 5, 5696.

[48] F. Leydier, C. Chizallet, A. Chaumonnot, M. Digne, E. Soyer, A.-A. Quoineaud, D. Costa, P. Raybaud, J. Catal. 2011, 284, 215.

[49] M. A. Ardagh, Z. Bo, S. L. Nauert, J. M. Notestein, ACS Catal. 2016, 6, 6156.

[50] Z. Weng, F. Zaera, ACS Catal. 2018, 8, 8513.

[51] J. Zakzeski, P. C. A. Bruijnincx, A. L. Jongerius, B. M. Weckhuysen, Chem. Rev. 2010, 110, 3552.

[52] L. Wu, J. S. Luterbacher, Chimia 2019, 73, 591, DOI: 10.2533/chimia.2019.1.

[53] M. V. Bykova, D. Yu. Ermakov, V. V. Kaichev, O. A. Bulavchenko, A. A. Saraev, M. Yu. Lebedev, V. A. Yakovlev, Appl. Catal. B: Environ. 2012, 113114, 296.

[54] P. M. de Souza, R. C. Rabelo-Neto, L. E. P. Borges, G. Jacobs, B. H. Davis, D. E. Resasco, F. B. Noronha, ACS Catal. 2017, 7, 2058.

[55] J. Zhang, B. Wang, E. Nikolla, J. W. Medlin, Angew. Chem. Int. Ed. 2017, 56,6594 .

[56] A. M. Robinson, J. E. Hensley, J. W. Medlin, ACS Catal. 2016, 6, 5026. 